\title{
Combining Exercise, Protein Supplementation and Electric Stimulation to Mitigate Muscle Wasting and Improve Outcomes for Survivors of Critical Illness - the ExPrES Study
}

\author{
Avelino Verceles ( $\square$ Avercele@som.umaryland.edu ) \\ University of Maryland Baltimore https://orcid.org/0000-0002-5267-6542

\section{Monica Serra} \\ University of Texas UTHSCSA: The University of Texas Health Science Center at San Antonio \\ Derik Davis \\ University of Maryland School of Medicine
}

Gad Alon

University of Maryland School of Medicine

Chris Wells

University of Maryland School of Medicine

Elizabeth Parker

University of Maryland School of Medicine

Michael L. Terrin

University of Maryland Medical Center

John Sorkin

University of Maryland Medical Center

Waqas Bhatti

University of Maryland Medical Center

Andrew P. Goldberg

University of Maryland Medical Center

\section{Research Article}

Keywords: ICU. Neuromuscular electrical stimulation, High protein supplement, Multimodal rehabilitation training, ICU acquired weakness, critical care nutrition

Posted Date: December 17th, 2021

DOI: https://doi.org/10.21203/rs.3.rs-1170718/v1 
License: (c) (i) This work is licensed under a Creative Commons Attribution 4.0 International License. Read Full License 


\section{Abstract}

Background: The combination of neuromuscular electrical stimulation (NMES) with high protein supplementation (HPRO) to preserve muscle mass and function has not been assessed in ICU patients. We compared the effects of a multimodal intervention combining NMES and HPRO with mobility and strength rehabilitation program (NMES+HPRO+PT) to standardized ICU care (SC).

Methods: Over 14 days the SC group received usual critical care and rehabilitation while the NMES+HPRO+PT received 30 minutes NMES twice daily for 10 days applied to the quadriceps and dorsiflexors bilaterally and a mean $1.3 \pm 0.4 \mathrm{HPRO} \mathrm{g} / \mathrm{kg}$ body weight in addition to SC. Nonresponsive patients received passive exercises and once responsive were encouraged to exercise actively. Primary outcome measures were muscle volume and cross-section area (CSA) measured using CT-imaging. Secondary outcomes included nutritional status, nitrogen balance, effect on delirium, and days on mechanical ventilation (MV).

Results: On day 14, the NMES+HPRO+PT group lost significantly less muscle volume of both thighs and lower legs compared to SC group. The mean combined left and right thigh CSA and volume of the NMES+HPRO+PT group was significantly larger than the SC group on day 14 . The nitrogen balance of the $S C$ group was negative throughout the study duration, while the NMES+HPRO+PT group was positive on days 5,9 , and 14 . At any time during their ICU stay SC patients experienced more delirium than the PT+NMES+HPRO group ( $46 \%$ vs $32 \%, p=0.09$ ) although not statistically significant. There were no differences between groups when comparing length of stay or days on MV.

Conclusion: The combination of NMES, HPRO and PT resulted in mitigation of lower extremity muscle loss and amelioration of clinical status of patients admitted to the ICU. The value of NMES, HPRO and PT independently in the initial and ongoing care of ICU survivors beyond 14 days of admission remains to be evaluated.

Trial Registration: Clinicaltrials.gov identifier: NCT3195127

\section{Background}

Older patients who suffer from critical illness, particularly those requiring mechanical ventilation (MV), are at high risk for skeletal muscle wasting and loss of physical function resulting from prolonged bed rest. This debilitated state can further perpetuate a prolonged intensive care unit (ICU) stay resulting in increased mortality. The mechanisms for this muscle wasting are multifactorial and include endotoxinmediated inflammation, nutritional inadequacy and altered substrate metabolism (1-5). Efforts at rehabilitating older, critically ill patients during an ICU admission vary from passive mobility and range of motion exercises in bed-bound patients (6-8) to progressive ambulation (9-11). Though active participation in limb strengthening, gait rehabilitation and endurance exercises during ICU admission are beneficial $(6,12)$, impaired consciousness, delirium and hemodynamic instability obviate the ability of 
critically ill patients to perform mobility-based maneuvers. Therefore, alternative rehabilitation strategies are needed preserve muscle mass and function in this high-risk population.

Neuromuscular electrical stimulation (NMES), a method which uses electrical impulses to elicit involuntary muscle contractions to reduce muscle loss, has gained much interest over the past decade as adjunctive rehabilitation therapy for hospitalized patients, including critically ill patients admitted to ICUs (13-17). The principal mechanism supporting the incorporation of electrically induced contraction into the care of these patients is the enhancement of metabolic exchange, augmentation of muscle blood flow and muscle fiber hypertrophy $(15,18,19)$. Though NMES appears to be a promising intervention to mitigate muscle atrophy associated with prolonged bedrest, less is known about its effects on the recovery of functional outcomes, especially in the face of nutritional deficit, similar to the undernourished state that occurs during critical illness.

Nutritional supplementation, specifically dietary protein intake, has received increasing attention as a strategy to preserve skeletal muscle health when combined with standardized ICU rehabilitation. In select non-ICU populations, the combination of high protein diets and rehabilitation interventions have demonstrated favorable treatment effects in terms of preservation of skeletal muscle mass, strength and function compared with either nutrition or rehabilitation alone $(20,21)$. Although it is recognized that nutritional optimization combined with activity and strength-oriented rehabilitation may yield the best outcomes (22), nutritional intake of critically ill patients is often below that prescribed by the registered dietitian due to unplanned interruption of feedings for procedures and feeding intolerance (23-25). Furthermore, providing the prescribed nutritional intake without the incorporation of effective exercise while bedbound will reduce the ability of muscle to effectively utilize amino acids as metabolic substrates needed to sustain an anabolic state and maintain skeletal muscle structure, mass and function (26).

Thus, the combination of NMES with high protein supplementation (HPRO) may be an ideal strategy for mitigating loss of muscle mass and preserving function, thereby shortening the duration of MV and ICU length of stay (LOS) in critically ill patients $(22,27)$. We hypothesized that NMES combined with high protein supplementation would attenuate the loss of muscle mass, maintain positive nitrogen balance, and improve clinical outcomes (reduce delirium, ventilator days and ICU LOS) compared to usual care. We assessed this by conducting a randomized pilot trial comparing the effects of a multimodal intervention combining a mobility and strength rehabilitation program (PT), NMES and high protein dietary supplementation (NMES+HPRO) to standardized ICU care (SC) on change in muscle mass and clinical outcomes.

\section{Methods}

Older ( $>50$ years), mechanically ventilated patients ( $\geq 24$ hours) were screened daily using the following eligibility criteria: pre-admission Barthel Index of $\geq 70$, ability to follow commands and able to perform physical therapy testing prior to ICU admission. Informed consent was obtained from those that met 
eligibility criteria or their legally authorized representative. Demographic data were collected from the electronic medical record (EMR). Actual patient height and weight were obtained while in bed using measuring tape and bed scale. APACHE II and Nutrition Risk in Critically ill (NUTRIC) score were calculated to categorize baseline severity of illness and nutritional risk (28).

\section{Assessments}

Measurements of thigh and lower leg muscle volume and cross-sectional area and testing of muscle strength and mobility were performed at baseline and repeated at day 7 and 14 of the intervention or at the time of discharge from the ICU if less than 14 days. On days 1, 5, 9 and 14, assessment of nitrogen balance and delirium occurred.

\section{Muscle Volume and Cross-Sectional Area (CSA)}

Study participants received volumetric non-contrast enhanced CT scans (Brilliance 64 scanner, Philips Healthcare, The Netherlands) from the hips to the ankles bilaterally to assess skeletal muscle CSA and volume of tissue. Skeletal muscle was considered in the range of -29 to +150 Hounsfield units $(29,30)$ using Medical Image Processing, Analysis and Visualization (MIPAV, version 7.0, NIH, Bethesda, Maryland) analytical software (31). CSA was measured as the sum of all muscles for the right and left thighs (where the middle slice corresponded to the level at one-third the distance from the lesser trochanter to articular surface of the ipsilateral femur (32) and lower legs (where the middle slice corresponding to the level at one-third the distance from the proximal articular surface to the distal articular surface of the ipsilateral tibia), separately, on three consecutive 10-mm axial CT slices. Using the same regions, thigh and lower leg volumes were each measured using Philips IntelliSpace Portal software (version 8.0, Philips Healthcare, The Netherlands).

\section{Muscle Strength and Mobility Testing}

A research physical therapist (PT) was responsible for measuring and recording muscle strength and mobility data, while a second therapist was responsible for administration of the multimodal therapy intervention for each patient (described below), assuring continuity of data collection, and independence of the intervention procedures to avoid intervention bias. However, some data could not be collected at baseline from patients who were comatose/sedated, medically unstable, or were too weak to perform the tests. A handheld Microfet ${ }^{\text {TM }}$ dynamometer (Hogganscientific.com) was used to assess hand grip and lower extremity strength, specifically muscular force generation of the knee and hip flexors and extensors. testing of the lower extremities, Locomotion function and ambulation was assessed using the Short Physical Performance Battery (SPPB). The Barthel Index was completed to assess functional independence.

\section{Nutritional Status}

Electronic records were reviewed to determine total daily volume of enteral feeds administered. Total daily energy and protein intake were calculated from standardized formulas using volume of enteral feeds in 
addition to the energy and protein from supplements. Recorded dietary intake included total caloric and macronutrient intake from intravenous medications (i.e, propofol, dextrose), as well as parenteral, enteral, and oral feedings. Nitrogen balance was calculated on days 1, 5, 9, and 14 from 24-hour urine collection for urine urea nitrogen measurements and known dietary intake.

\section{Clinical Outcomes}

After obtaining all baseline measures, patients were randomized to either SC or NMES+HPRO+ PT groups. Data extracted from the electronic medical record upon discharge included the number of physical therapy and occupational therapy sessions, incidence of delirium on days 1,5,9,14 (based on the Confusion Assessment Method(33)), recommended and actual discharge disposition, hospital and ICU length of stay, and days on ventilator.

\section{Interventions}

\section{Standardized Care (SC) Group}

The SC group received standard, condition-specific ICU medical management in addition to ICU-protocoldriven management of sedation, ventilator weaning, glucose control, nutritional support, and environmental optimization. Standard physical therapy and occupational therapy was provided by trained hospital therapists per usual practice of Rehabilitation Services. Dietary recommendations for all patients were calculated by the ICU Registered Dietician (RD) using the Penn State Equation adjusting for body temperature and minute ventilation (34). Recommended protein intake was calculated per usual hospital protocol using ASPEN guidelines (35) and depended on severity of illness and BMI.

\section{NMES+HPRO+PT Group}

The NMES+HPRO+PT group was provided a multimodal rehabilitation program as described in a recent publication (12) In addition, the group received SC physical therapy by the hospital rehabilitation services. The multimodal rehabilitation program was delivered by a research PT who did not participate in SC. The PT intervention was based on exercise physiology principles with sufficient intensity, duration, frequency, and recovery period as previously published [10]. Patients in the NMES+HPRO+PT group were seen twice a day for 30 minutes each, up to 5 days per week. One session included an individualized progressive PT rehabilitation program providing muscle strength and endurance training and focused on restoring sit to stand and ambulation ability concurrent with a 30-minute NMES session. Full participation in this daily session was limited by each patient's physical ability on a given day. The second daily session consisted of a second NMES treatment without physical exercises. The goal was for the patients to receive a total of 20 NMES sessions in a 14-day period (1.4 sessions/day), including 10 simultaneously with physical therapy, throughout the study duration.

NMES was provided using a wireless wearable functional electrical stimulation system (Bioness L300 Plus ${ }^{\mathrm{TM}}$ ) applied to the quadriceps and dorsiflexor muscles of both lower extremities using water-based surface electrodes twice daily for 14 days or until discharge from the ICU. The parameters used included 
symmetric biphasic waveform pulses of $300 \mu s e c$ phase duration and pulse rate of 30 pulses per second. Contraction and relaxation times were each set at $10 \mathrm{sec}$ and all 4 muscle groups were stimulated concurrently. Each session's stimulation data of each muscle were quantified as stimulation dose (in microcoulombs) using the formula: pulse duration (PD) $X$ pulse rate (PR) $X$ peak current intensity (I) $X$ treatment time $(T)$. Stimulation intensity during each session was adjusted by the research therapist to assure as strong as possible visible muscle contraction tolerated. NMES was paused during ambulation activities to assure subject's safety. For subjects who were sedated, NMES sessions were provided twice a day for 30 minutes at an intensity to elicit the highest tolerated overt intermittent contractions.

Protein recommendations for the HPRO study group were prescribed based on 1.75 grams of protein per kilogram of actual body weight per day. After accounting for protein in the parenteral, enteral, and oral feeds, a powdered whey protein supplement (Optimum Nutrition, INC, Downers Grove, IL) was provided daily to supply the remaining protein required to achieve the total protein intake recommendations. The protein supplement was mixed with $40 \mathrm{ml}$ of water and was administered by nursing staff via enteric access. Any additional protein supplements recommended by the ICU RD were not provided to HPRO group.

\section{Statistical Analyses}

Data are expressed as mean \pm standard deviation, medians with interquartile ranges, or counts with percentages. Pearson's chi square test or Fisher's exact test, Student's t-test, and the Wilcoxon rank-sum tests compared baseline characteristics, including NUTRIC and APACHE II scores and BMI (SAS 9.4, Cary, NC, USA).

Mixed effects linear regression (SAS proc Mixed, with a repeated statement), was used to model the value of the outcome variable of interest at baseline, 7 and 14 days. AICC (a modification of Akaki's information criteria $(36,37)$ ) was used to select the covariance structure (compound symmetry vs. first-order autoregressive) that best fits the model. Within each covariance structure, a likelihood ratio test was used to choose between a model adjusted for initial value of the dependent variable, age, sex, ethnicity, intervention, time-point and an intervention*time-point interaction vs. a model adjusted for initial value of the dependent variable, intervention, time-point and an intervention*time-point interaction. Least square means were used to compute the value of the outcome measure at each time point. Linear contrasts were used to compute the changes from baseline to day 7 and from baseline to day 14 .

\section{Results}

\section{Baseline Demographics}

From May 2016 to March 2018, 350 patients were screened for eligibility and 46 were found to be eligible; consent was unable to be obtained in 7 patients. Of the 39 patients enrolled, 23 were randomized to SC and 16 to NMES+HPRO+PT. At baseline, patients in both groups were similar in age, race and sex (Table 1). Both groups had comparable APACHE II scores, NUTRIC score and Barthel Indices (Table 1). The 
leading ICU admission diagnosis was acute respiratory failure in both the SC (83\%) and PT+NMES+HPRO (81\%) groups.

Table 1

Demographics and Characteristics of Study Patients

\begin{tabular}{|llll|}
\hline & $\begin{array}{l}\text { SC } \\
(\mathbf{n = 2 3 )}\end{array}$ & $\begin{array}{l}\text { PT + NMES + HPRO } \\
(\mathbf{n = 1 6 )}\end{array}$ & p-value \\
\hline Age (years) & $62 \pm 9.3$ & $62 \pm 9.3$ & 0.99 \\
\hline Sex & & & 0.69 \\
\hline Male & $10(43 \%)$ & $8(50 \%)$ & \\
\hline Female & $13(57 \%)$ & $8(50 \%)$ & 0.35 \\
\hline Race & & & \\
\hline African American & $9(39 \%)$ & $10(63 \%)$ & 0.70 \\
\hline Caucasian & $11(48 \%)$ & $5(31 \%)$ & 0.29 \\
\hline Other & $3(13 \%)$ & $1(6 \%)$ & 0.47 \\
\hline BMI (kg/m $\left.{ }^{2}\right)$ & $30 \pm 6.6$ & $29 \pm 5.5$ & 0.90 \\
\hline APACHE II Score & $15.4 \pm 7.4$ & $17.8 \pm 5.5$ & 0.83 \\
\hline NUTRIC Score & $3.6 \pm 1.5$ & $3.9 \pm 1.7$ & \\
\hline Barthel Index & $93.0 \pm 9.5$ & $93.4 \pm 10.0$ & \\
\hline Primary Diagnosis & & & \\
\hline Respiratory & $19(83 \%)$ & $13(81 \%)$ & \\
\hline Cardiac & $0(0 \%)$ & $0(0 \%)$ & \\
\hline Neurological & $1(4 \%)$ & $0(0 \%)$ & \\
\hline Other & $3(13 \%)$ & $3(19 \%)$ & \\
\hline *Data expressed as $\mathrm{n}(\%)$ or mean \pm standard deviation unless otherwise noted. & \\
\hline
\end{tabular}

\section{Effects of the Intervention}

Seventeen of 23 and 11 of 16 patients completed testing on day 7, and 11 and 6 patients completed testing on day 14 for the SC and PT+NMES+HPRO groups, respectively. Both groups received similar number of usual care therapy sessions conducted by the ICU rehabilitation staff. Sessions were missed 
because of patient unresponsiveness (comatose or sedated), hemodynamic or respiratory instability, or the patient being off the unit for a procedure or diagnostic test. By design, the NMES+HPRO+PT group received an average of 5.6 extra PT sessions and 10 NMES sessions, more calories (15.3 \pm 6.8 vs $20.1 \pm$ $7.5 \mathrm{kcal} / \mathrm{kg}, \mathrm{p}=0.05)$ and protein $(0.8 \pm 0.4 \mathrm{vs} 1.3 \pm 0.4 \mathrm{~g} / \mathrm{kg} / \mathrm{d}(\mathrm{p}=0.003)$ than the SC group (Table 2).

Table 2

Physical Therapy, Neuromuscular Electric Stimulation and Nutrition Delivery

\begin{tabular}{|c|c|c|c|}
\hline & $S C(n=21)$ & PT+NMES+HPRO $(n=16)$ & p-value \\
\hline \multicolumn{4}{|l|}{ Rehabilitation Program- } \\
\hline Standardized Care (SC) & $3.2 \pm 3.1$ & $4.1 \pm 2.2$ & 0.35 \\
\hline \multicolumn{4}{|l|}{ Sessions/Patient } \\
\hline Sessions/Day & $0.3 \pm 0.3$ & $0.3 \pm 0.2$ & 0.78 \\
\hline Experimental & N/A & $8.2 \pm 2.0$ & \\
\hline Sessions Prescribed & & $5.6 \pm 3.3$ & \\
\hline \multicolumn{4}{|l|}{ Sessions Received } \\
\hline \multicolumn{4}{|l|}{ NMES } \\
\hline Prescribed \# Sessions & N/A & $10.1 \pm 4.5$ & \\
\hline \multicolumn{4}{|l|}{ Received } \\
\hline Prescribed \# Sessions/day & $\mathrm{N} / \mathrm{A}$ & $0.8 \pm 0.3$ & \\
\hline \multicolumn{4}{|l|}{ Received (max 14) } \\
\hline \% Prescribed Sessions & $\mathrm{N} / \mathrm{A}$ & $59 \pm 23$ & \\
\hline \multicolumn{4}{|l|}{ Received } \\
\hline Total Charge (millicoul) & $\mathrm{N} / \mathrm{A}$ & $9441.0 \pm 6862.7$ & \\
\hline \multicolumn{4}{|l|}{ Nutrition } \\
\hline Prescribed & $21.5 \pm 4.8$ & $22.7 \pm 4.1$ & 0.44 \\
\hline Calories/kg & $1.3 \pm 0.2$ & $1.4 \pm 0.2$ & 0.48 \\
\hline \multicolumn{4}{|l|}{ Protein/kg } \\
\hline Received & $15.3 \pm 6.8$ & $20.1 \pm 7.5$ & 0.05 \\
\hline Calories/kg & $0.8 \pm 0.4$ & $1.3 \pm 0.4$ & 0.003 \\
\hline Protein/kg & & & \\
\hline
\end{tabular}


Table 3. Thigh and Lower Leg Muscle Imaging - Cross Sectional Area and Volume 
Cross Sectional Area $\left(\mathrm{cm}^{2}\right)$

\begin{tabular}{llllll}
\multicolumn{2}{l}{ Absolute Value } & \multicolumn{5}{c}{ Change (\%) } \\
SC & PT+NMES+HPRO & $\begin{array}{l}\mathrm{p}- \\
\text { value }\end{array}$ & SC & PT+NMES+HPRO & $\begin{array}{l}\mathrm{p}- \\
\text { value }\end{array}$
\end{tabular}

Thigh

\begin{tabular}{|c|c|c|c|c|c|c|c|}
\hline Day & & & & Day & & & \\
\hline 0 & $111.9 \pm 1.9$ & $112.3 \pm 2.2$ & 0.90 & $0-7$ & $\begin{array}{l}-15.9 \\
(-14.2)\end{array}$ & $-13.0(-11.7)$ & 0.51 \\
\hline 7 & $96.0 \pm 2.1$ & $99.2 \pm 2.2$ & 0.29 & $\begin{array}{l}0- \\
14\end{array}$ & $\begin{array}{l}-26.2 \\
(-23.4)\end{array}$ & $-13.8(-12.4)$ & 0.08 \\
\hline
\end{tabular}

$14 \quad 85.7 \pm 3.1 \quad 98.4 \pm 2.9 \quad 0.004$

Lower Leg

Day

Day

$\begin{array}{llllllll}0 & 51.9 \pm 1.1 & 51.9 \pm 1.2 & 0.99 & 0-7 & -3.2(-6.2) & -2.1(-4.0) & 0.55 \\ 7 & 48.7 \pm 1.2 & 49.8 \pm 1.2 & 0.51 & \begin{array}{l}0- \\ 14\end{array} & -6.7(-11.7) & +0.2(+0.4) & 0.08\end{array}$

14

$\begin{array}{lll}45.2 \pm 1.7 & 52.1 \pm 1.6 & 0.005 \\ & \text { Volume }\left(\mathrm{cm}^{3}\right)\end{array}$

Absolute Value

SC

NMES+HPRO

$\mathrm{p}-$
value

Change (\%)

SC NMES+HPRO

p-

value

Thigh

Day

Day

$\begin{array}{llllllll}0 & 2245.8 \pm & 2261.5 \pm 40.0 & 0.77 & 0-7 & -193.5 & -198.2(-8.8) & 0.87 \\ & 35.6 & & & & (-8.6) & & \\ 7 & 2052.3 \pm & 2063.4 \pm 40.0 & 0.84 & \begin{array}{l}0- \\ 14\end{array} & \begin{array}{l}-471.7 \\ (-21.0)\end{array} & -190.1(-8.4) & 0.03 \\ & 38.5 & & & 14 & \end{array}$

$14 \quad 1774.1 \pm \quad 2071.5 \pm 53.5 \quad<0.001$

56.1

Lower Leg

SC $=$ Standard care, PT+NMES+HPRO = Physical Therapy, Neuromuscular Electric Stimulation and High Protein Supplementation. All statistics expressed as mean \pm SE. Sample sizes at Day 0 were 23 and 16 in SC and PT+NMES+HPRO respectively. On day 7, these numbers dropped to 17 and 11, and dropped further to 11 and 8 on day 14 . 


\begin{tabular}{|c|c|c|c|c|c|c|c|}
\hline \multicolumn{4}{|c|}{ Day } & \multicolumn{4}{|c|}{ Day } \\
\hline 0 & $\begin{array}{l}932.2 \pm \\
20.2\end{array}$ & $938.9 \pm 22.6$ & 0.83 & $0-7$ & $-64.0(-6.9)$ & $-34.9(-3.7)$ & 0.45 \\
\hline 7 & $\begin{array}{l}868.2 \pm \\
21.6\end{array}$ & $904.0 \pm 22.6$ & 0.26 & $\begin{array}{l}0- \\
14\end{array}$ & $\begin{array}{l}-142.9 \\
(-15.3)\end{array}$ & $-11.0(-1.2)$ & 0.05 \\
\hline 14 & $\begin{array}{l}789.4 \pm \\
32.5\end{array}$ & $927.9 \pm 29.1$ & 0.003 & & & & \\
\hline \multicolumn{8}{|c|}{$\begin{array}{l}\text { SC }=\text { Standard care, PT+NMES }+ \text { HPRO = Physical Therapy, Neuromuscular Electric Stimulation and } \\
\text { High Protein Supplementation. All statistics expressed as mean } \pm \text { SE. Sample sizes at Day } 0 \text { were } 23 \\
\text { and } 16 \text { in SC and PT+NMES+HPRO respectively. On day } 7 \text {, these numbers dropped to } 17 \text { and } 11 \text {, and } \\
\text { dropped further to } 11 \text { and } 8 \text { on day } 14 \text {. }\end{array}$} \\
\hline
\end{tabular}

\section{Muscle volume and cross-sectional area (CSA)}

The muscle CSA and volumes were comparable in the HPRO+NMES and SC groups at baseline (Table 3). Change from baseline in CSA and volume of the thighs and lower legs did not differ between groups by day 7. However, on day 14 , the SC group lost more muscle when comparing thigh and lower leg volume compared to the NMES+HPRO +PT group (thigh $-21.0 \%$ vs. $-8.4 \%$, $p=0.03$; lower leg $-15.3 \%$ vs. $-1.2 \%$, $\mathrm{p}=0.05$, Table 3). The SC group also experienced greater muscle loss when comparing thigh cross sectional area compared to the NMES+HPRO +PT group, although not statistically significant (thigh $-26.2 \%$ vs. $-13.8 \%, p=0.08)$. When analyzing lower leg cross sectional area, the SC group continued to lose muscle mass while the NMES+HPRO group gained lower leg volume over the 14-day time period (-15.3\% vs. $1.2 \%, p=0.08)$.

\section{Muscle Strength and Mobility}

Both groups had very similar values of loss of muscle strength and the short physical performance battery (SPPB) scores throughout the 14 days of data collection. These were not reported or analyzed due to the low number of patients being able to perform serial follow up maneuvers because of were coma/sedation, medical instability, or weakness in the early days of ICU admission and critical illness, and in part due to early discharge from the ICU.

\section{Nutritional Status}

There was a significant difference in the amount of calories $/ \mathrm{kg}$ and protein $/ \mathrm{kg}$ intake between the groups (Table 2). The nitrogen balance of the SC group was negative across the study duration, while the PT+NMES+HPRO group returned to positive balance on Day 5,9 , and 14 , with significant differences in nitrogen balance between groups recorded on Day 9 (Table 4). 
Table 4

Nitrogen Balance Between Groups Over 2 Weeks

\begin{tabular}{|llll|}
\hline Nitrogen Balance & $\begin{array}{l}\text { SC } \\
(\text { mean } \pm \text { SD) }(\mathbf{n})\end{array}$ & $\begin{array}{l}\text { NMES+HPRO +PT } \\
(\text { mean } \pm \text { SD) }(\mathbf{n})\end{array}$ & p-value \\
\hline Day 1 & $-4.60 \pm 8.48(23)$ & $-0.99 \pm 5.76(16)$ & 0.16 \\
\hline Day 5 & $-2.88 \pm 7.81(18)$ & $1.35 \pm 10.68(16)$ & 0.19 \\
\hline Day 9 & $-2.27 \pm 9.01(14)$ & $7.38 \pm 7.31(11)$ & $0.009 *$ \\
\hline Day 14 & $-3.73 \pm 11.09(11)$ & $1.45 \pm 10.23(8)$ & 0.36 \\
\hline Proportion Testing CAM + for Delirium & & \\
\hline
\end{tabular}

\section{Clinical ICU Outcomes}

At all designated time points, the SC group had a higher proportion of patients test positive for delirium compared to the HPRO+NMES+PT group, although no significant differences in CAM score were noted at any time (Table 4).

There was no difference in the ICU LOS. Although the mean days on the ventilator was higher in the SC group, this difference also did not reach statistical significance ( $10.5 \pm 9.3$ vs. $6.9 \pm 5.0$ days, $p=0.13$, Table 5). There was no statistically significant difference between groups in the proportion of patients who went home, or to a skilled nursing facility or other hospital/facility.

Table 5

Disposition Status (60 day outcome)

\begin{tabular}{|llll|}
\hline & $\begin{array}{l}\text { Control } \\
(\mathbf{n = 2 3})\end{array}$ & $\begin{array}{l}\text { Intervention } \\
(\mathbf{n = 1 6 )}\end{array}$ & p-value \\
\hline Disposition & & & 0.75 \\
\hline Home & $13(57 \%)$ & $8(50 \%)$ & \\
\hline Other than home & $10(43 \%)$ & $8(50 \%)$ & \\
\hline Hospital LOS (days) & $19.1 \pm 11.1$ & $19.1 \pm 9.6$ & 0.99 \\
\hline ICU LOS (days) & $11.5 \pm 9.2$ & $10.6 \pm 6.3$ & 0.74 \\
\hline Ventilator Duration (days) & $10.5 \pm 9.3$ & $6.9 \pm 5.0$ & 0.13 \\
\hline
\end{tabular}

\section{Discussion}


The multipronged intervention presented in this pilot study presents a novel approach testing additive effects of NMES and high protein supplementation combined with multimodal physical rehabilitation on muscle loss and clinical and functional outcomes. The findings demonstrate the favorable effects of this intervention to attenuate lower extremity muscle loss in older and middle age mechanically ventilated survivors, admitted to a medical ICU. Further, the outcomes show the intervention was associated with significant improvements in nitrogen balance and muscle mass and a reduction in the incidence of delirium using the Confusion Assessment Method (CAM). While a small number of studies show favorable independent benefits of NMES or NMES combined with exercise on the recovery of muscle strength $(13-17,38)$, there are few studies other than one in ambulatory patients with COPD (39) that examine the effects of combining NMES with caloric and protein supplementation on muscle mass and function. Thus, the findings of this investigation support a new, efficacious treatment strategy for the management of critically ill patients.

Our findings are consistent with those of previous studies which concluded that physical rehabilitation and early mobility are feasible and safe interventions for mechanically ventilated ICU patients $(6,8,40)$. However, much of the benefit is dependent on patients' active participation. In the early days of ICU hospitalization and often for several days, critically ill patients are unable to actively participate in PT due to impaired consciousness, sedation, delirium, or general frailty $(41,42)$. Several studies report little to no physical benefit for severely debilitated, critically ill patients from therapeutic passive range of motion and change in bed position; thus, these patients are most susceptible to developing post ICU syndrome and associated neuromuscular weakness and atrophy $(43,44)$. Recent studies demonstrate that NMES is a noninvasive therapeutic intervention that can restore muscle strength, while enhancing peripheral blood flow, promote skeletal muscle angiogenesis, and decrease inflammation thereby potentially reducing the impact of sepsis in patients unable to exercise voluntarily $(13-19,38,45,46)$. This suggests that the incorporation of NMES, independent of the patients' level of consciousness or delirium status, is a feasible, practical treatment adjunct to provide uniform physical rehabilitation to most critically ill patients $(15,18,19,46-49)$. However, the magnitude of the benefits of NMES in minimizing muscle atrophy and promoting muscle strength gains in critically ill patients varies widely amongst most studies, mostly due to differences in delivery, methodology and patient selection $(15,17,45-48)$. Thus, NMES demonstrates potential as a treatment modality to improve critical care outcomes and prevent post-ICU syndrome $(50,51)$.

Our study encountered challenges with respect to obtaining functional data over time. One factor that limited our team's ability to obtain complete data was the study design that incorporated multiple serial muscle strength measurements using a hand-held dynamometer instrument, technique that were adopted from one of our previous studies (12). Because this maneuver required voluntary effort, those who were comatose or sedated during their ICU admission could not complete a proper assessment. Additionally, it turned out that a small sample size ( $n=11$ intervention and 8 controls) remained hospitalized at the last testing day. This was the result of early discharge of patients from the ICU, scheduling conflicts with diagnostic testing or procedures, inability to participate due to sedation, coma or weakness resulting in missing strength testing data not warranting statistical comparison. In contrast to our findings a number 
of studies evaluating NMES-based interventions did report increase of muscle strength in ICU patients $(13,17,45)$. However, they assessed strength using manual muscle testing or the medical research council (MRC) scores that tend to have less test-retest variance and thus require a smaller sample size.

In our study, the intervention and standard care groups did not differ in disposition at discharge from the hospital, length of stay (LOS) in the ICU, or time on ventilator support. These data contrast the results of an earlier investigation that reported significant difference weaning from mechanical ventilation ( $87 \% \mathrm{vs.}$ $41 \%$ ) and more patients discharged home than usual care (53\% vs. $12 \%$ ) when comparing the efficacy of multimodal rehabilitation program alone to usual care. The study population in the aforementioned study were long-term acute care hospital (LTACH) patients (12) as opposed to our population, who were medical ICU patients. The difference in outcomes could potentially be explained by severity of illness and co-morbidities of an ICU population when compared to a less severely ill LTACH population.

Treatment efficacy may also be impacted by poor nutritional status of patients (52) and inconsistent patient adherence to the recommended nutritional supplement. This study compared protein supplementation administered in standard ICU care $(0.8 \pm 0.4)$ to the high dose protein $(1.3 \pm 0.4)$ of our experimental group. The protein delivered to patients in our intervention group were comparable to the recommended protein intake doses of ICU patients in other nutritional intervention studies and consistent with the recommendations of the American Society of Parenteral and Enteral Nutrition $(23,24,35,53-57)$. The nutritional supplementation provided ample calories and protein to the HRPO+NMES+PT group to reduce muscle catabolism and prevent wasting, while the SC group started and continued to be in negative nitrogen balance with muscle loss over the course of the study. However, the question whether either NMES or HPRO or both are necessary to restore nitrogen balance in critically ill, MV patients will require a randomized study, as will the hypothesis that optimal nitrogen balance may lead to better clinical outcomes (56). The PT+NMES+HPRO protocol resulted in better clinical outcomes but found no correlation between changes in muscle volume or CSA with nitrogen balance supporting the concept that nitrogen balance and muscle strength recovery may be independent variables in non-mobile patients ICU patients.

We acknowledge several shortcomings inherent in our study. The discharge of patients from the initial numbers of 23 (SC) and 16 (PT+NMES+HPRO) at baseline to only 11 and 8 at study end point was not expected and reduced the statistical power in our analyses. As discussed, several unanticipated constrains resulted in limited dose of the NMES application due in part to the 1:9 therapist to patient ratio. To overcome these two short comings future study designs should include additional NMES sessions each day that may be delivered by other ICU team members in addition to the physical therapists, like nurses and patient care technicians. Another limitation inherent in the study design included the inability of our study to compare individual modalities or other combinations of intervention including HPRO+PT without NMES, or NMES alone. The decision not to include these other groups was due to the pilot nature of this study which was primarily limited by support and ability to recruit enough subjects in the period allocated to this trial. 


\section{Conclusion}

In this pilot trial of critically ill, mechanically ventilated patients, the addition of physical therapy, neuromuscular electric stimulation and high protein nutritional supplementation to standard critical care resulted in the restoration of positive NB, which was associated with an increase in lower extremity muscle volume and cross-sectional area when compared standard medical care. Additionally, the patients in the intervention group experienced less delirium and time requiring mechanical ventilation. Larger, randomized future studies are needed to determine whether the components of this multimodal intervention will yield similar benefits independently of one another, and if continuing this intervention longer than 14 days confers additional health benefits.

\section{Abbreviations}

NMES - neuromuscular electrical stimulation

HPRO - high protein supplementation

PT - physical therapy

SC - standard care

LOS - length of stay

EMR - electronic medical record

NUTRIC - Nutrition Risk in Critically ill

MRC - medical research council

LTACH - long-term acute care hospital

PD - pulse duration

PR - pulse rate

CAM - confusion Assessment Method

CSA - cross-sectional area

SPPB - short physical performance battery

\section{Declarations}

Ethics Approval and Consent to Participate 
This study was approved by the IRB of University of Maryland Medical Center

\section{Consent for Publication}

Not Applicable

Availability of data and materials

The datasets used and/or analyzed during the current study are available from the corresponding author on reasonable request.

Competing Interests

The authors declare that they have no competing interests

\section{Funding}

AV, EP, AG, MT, CW, and JS were funded by R21AG050890 and University of Maryland Claude D. Pepper Older Americans Independence Center (NIA P30AG028747). Dr. Serra received funding from Career Development Award IK2 RX-000944,U.S. Department of Veterans Affairs Rehabilitation R\&D Service.

\section{Authors' contributions}

Literature search: AV, WB; Study concept and design: AV, GA, MT, AG; Data acquisition or interpretation of data: AV, MS, DD, EP, CW, MT, JS, WB; Drafting of the manuscript: AV, GA, AG; Critical revision of manuscript: All authors; Statistical analysis: AV, JS, WB; Study supervision: AV, EP, MT, AG.

Acknowledgements

Not Applicable

\section{References}

1. Puthucheary ZA, McPhail MJ, Hart N: Acute muscle wasting among critically ill patients-reply. JAMA 2014; 311(6):622-623

2. Klaude M, Mori M, Tjader I, Gustafsson T, et al: Protein metabolism and gene expression in skeletal muscle of critically ill patients with sepsis. Clin Sci (Lond) 2012; 122(3):133-142

3. Paddon-Jones D, Sheffield-Moore M, Cree MG, Hewlings SJ, et al: Atrophy and impaired muscle protein synthesis during prolonged inactivity and stress. J Clin Endocrinol Metab 2006; 91(12):48364841

4. Essen P, McNurlan MA, Gamrin L, Hunter K, et al: Tissue protein synthesis rates in critically ill patients. Crit Care Med 1998; 26(1):92-100 
5. Helliwell TR, Coakley JH, Wagenmakers AJ, Griffiths RD, et al: Necrotizing myopathy in critically-ill patients. J Pathol 1991; 164(4):307-314

6. McWilliams D, Jones $C$, Atkins $G$, Hodson J, et al: Earlier and enhanced rehabilitation of mechanically ventilated patients in critical care: A feasibility randomised controlled trial. J Crit Care 2018; 44:407412

7. Bakhru RN, McWilliams DJ, Wiebe DJ, Spuhler VJ, et al: Intensive Care Unit Structure Variation and Implications for Early Mobilization Practices. An International Survey. Ann Am Thorac Soc 2016; 13(9):1527-1537

8. Morris PE, Griffin L, Berry M, Thompson C, et al: Receiving early mobility during an intensive care unit admission is a predictor of improved outcomes in acute respiratory failure. Am J Med Sci 2011; 341(5):373-377

9. Apostolakis E, Papakonstantinou NA, Baikoussis NG, Papadopoulos G: Intensive care unit-related generalized neuromuscular weakness due to critical illness polyneuropathy/myopathy in critically ill patients. J Anesth 2015; 29(1):112-121

10. Pohlman MC, Schweickert WD, Pohlman AS, Nigos C, et al: Feasibility of physical and occupational therapy beginning from initiation of mechanical ventilation. Crit Care Med 2010; 38(11):2089-2094

11. Rochester CL: Rehabilitation in the intensive care unit. Semin Respir Crit Care Med 2009; 30(6):656669

12. Verceles AC, Wells CL, Sorkin JD, Terrin ML, et al: A multimodal rehabilitation program for patients with ICU acquired weakness improves ventilator weaning and discharge home. J Crit Care 2018; 47:204-210

13. Akar O, Gunay E, Sarinc Ulasli S, Ulasli AM, et al: Efficacy of neuromuscular electrical stimulation in patients with COPD followed in intensive care unit. Clin Respir J 2017; 11(6):743-750

14. Iwatsu K, Yamada S, lida Y, Sampei H, et al: Feasibility of neuromuscular electrical stimulation immediately after cardiovascular surgery. Arch Phys Med Rehabil 2015; 96(1):63-68

15. Dirks ML, Hansen D, Van Assche A, Dendale P, et al: Neuromuscular electrical stimulation prevents muscle wasting in critically ill comatose patients. Clin Sci (Lond) 2015; 128(6):357-365

16. Segers J, Hermans G, Bruyninckx F, Meyfroidt G, et al: Feasibility of neuromuscular electrical stimulation in critically ill patients. J Crit Care 2014; 29(6):1082-1088

17. Hirose T, Shiozaki T, Shimizu K, Mouri T, et al: The effect of electrical muscle stimulation on the prevention of disuse muscle atrophy in patients with consciousness disturbance in the intensive care unit. J Crit Care 2013; 28(4):536 e531-537

18. Dall' Acqua AM, Sachetti A, Santos LJ, Lemos FA, et al: Use of neuromuscular electrical stimulation to preserve the thickness of abdominal and chest muscles of critically ill patients: A randomized clinical trial. J Rehabil Med 2017; 49(1):40-48

19. Stefanou C, Karatzanos E, Mitsiou G, Psarra K, et al: Neuromuscular electrical stimulation acutely mobilizes endothelial progenitor cells in critically ill patients with sepsis. Ann Intensive Care 2016; $6(1): 21$ 
20. Morton RW, Traylor DA, Weijs PJM, Phillips SM: Defining anabolic resistance: implications for delivery of clinical care nutrition. Curr Opin Crit Care 2018; 24(2):124-130

21. Morton RW, Murphy KT, McKellar SR, Schoenfeld BJ, et al: A systematic review, meta-analysis and meta-regression of the effect of protein supplementation on resistance training-induced gains in muscle mass and strength in healthy adults. Br J Sports Med 2018; 52(6):376-384

22. Parry SM, Chapple LS, Mourtzakis M: Exploring the Potential Effectiveness of Combining Optimal Nutrition With Electrical Stimulation to Maintain Muscle Health in Critical Illness: A Narrative Review. Nutr Clin Pract 2018; 33(6):772-789

23. Koekkoek W, van Setten CHC, Olthof LE, Kars J, et al: Timing of PROTein INtake and clinical outcomes of adult critically ill patients on prolonged mechanical VENTilation: The PROTINVENT retrospective study. Clin Nutr 2018

24. Phillips SM, Dickerson RN, Moore FA, Paddon-Jones D, et al: Protein Turnover and Metabolism in the Elderly Intensive Care Unit Patient. Nutr Clin Pract 2017; 32(1_suppl):112S-120S

25. Compher C, Chittams J, Sammarco T, Nicolo M, et al: Greater Protein and Energy Intake May Be Associated With Improved Mortality in Higher Risk Critically III Patients: A Multicenter, Multinational Observational Study. Crit Care Med 2017; 45(2):156-163

26. Lambell KJ, King SJ, Forsyth AK, Tierney AC: Association of Energy and Protein Delivery on Skeletal Muscle Mass Changes in Critically III Adults: A Systematic Review. JPEN J Parenter Enteral Nutr 2018; 42(7):1112-1122

27. Heyland DK, Day A, Clarke GJ, Hough CT, et al: Nutrition and Exercise in Critical Illness Trial (NEXIS Trial): a protocol of a multicentred, randomised controlled trial of combined cycle ergometry and amino acid supplementation commenced early during critical illness. BMJ Open 2019; 9(7):e027893

28. Singer $P$, Blaser AR, Berger MM, Alhazzani W, et al: ESPEN guideline on clinical nutrition in the intensive care unit. Clin Nutr 2019; 38(1):48-79

29. Mitsiopoulos N, Baumgartner RN, Heymsfield SB, Lyons W, et al: Cadaver validation of skeletal muscle measurement by magnetic resonance imaging and computerized tomography. $J$ Appl Physiol (1985) 1998; 85(1):115-122

30. Prado CM, Lieffers JR, McCargar LJ, Reiman T, et al: Prevalence and clinical implications of sarcopenic obesity in patients with solid tumours of the respiratory and gastrointestinal tracts: a population-based study. The Lancet Oncology 2008; 9(7):629-635

31. Ryan AS, Buscemi A, Forrester L, Hafer-Macko CE, et al: Atrophy and intramuscular fat in specific muscles of the thigh: associated weakness and hyperinsulinemia in stroke survivors. Neurorehabil Neural Repair 2011; 25(9):865-872

32. Messier SP, Mihalko SL, Beavers DP, Nicklas BJ, et al: Strength Training for Arthritis Trial (START): design and rationale. BMC Musculoskelet Disord 2013; 14:208

33. Ely EW, Margolin R, Francis J, May L, et al: Evaluation of delirium in critically ill patients: validation of the Confusion Assessment Method for the Intensive Care Unit (CAM-ICU). Crit Care Med 2001; 29(7):1370-1379 
34. Ashcraft CM, Frankenfield DC: Energy expenditure during barbiturate coma. Nutr Clin Pract 2013; 28(5):603-608

35. McClave SA, Taylor BE, Martindale RG, Warren MM, et al: Guidelines for the Provision and Assessment of Nutrition Support Therapy in the Adult Critically III Patient: Society of Critical Care Medicine (SCCM) and American Society for Parenteral and Enteral Nutrition (A.S.P.E.N.). JPEN J Parenter Enteral Nutr 2016; 40(2):159-211

36. Hurvich CM, Tsai, C.L. : Regression and time series model selection in small samples. Biometrika 1989; 76 (2):297-307

37. Akaike H: IEEE Transactions on Automatic Control. A New Look at the Statistical Model Identification 1974; C(19):716-723

38. Dos Santos FV, Cipriano G, Jr., Vieira L, Guntzel Chiappa AM, et al: Neuromuscular electrical stimulation combined with exercise decreases duration of mechanical ventilation in ICU patients: A randomized controlled trial. Physiother Theory Pract 2020; 36(5):580-588

39. Latimer LE, Constantin D, Greening NJ, Calvert L, et al: Impact of transcutaneous neuromuscular electrical stimulation or resistance exercise on skeletal muscle mRNA expression in COPD. Int $J$ Chron Obstruct Pulmon Dis 2019; 14:1355-1364

40. Needham DM: Mobilizing patients in the intensive care unit: improving neuromuscular weakness and physical function. JAMA 2008; 300(14):1685-1690

41. Miranda Rocha AR, Martinez BP, Maldaner da Silva VZ, Forgiarini Junior LA: Early mobilization: Why, what for and how? Med Intensiva 2017; 41(7):429-436

42. Kho ME, Molloy AJ, Clarke FJ, Ajami D, et al: TryCYCLE: A Prospective Study of the Safety and Feasibility of Early In-Bed Cycling in Mechanically Ventilated Patients. PLoS One 2016; 11(12):e0167561

43. Jolley SE, Moss M, Needham DM, Caldwell E, et al: Point Prevalence Study of Mobilization Practices for Acute Respiratory Failure Patients in the United States. Crit Care Med 2017; 45(2):205-215

44. Koukourikos K, Tsaloglidou A, Kourkouta L: Muscle atrophy in intensive care unit patients. Acta Inform Med 2014; 22(6):406-410

45. Leite MA, Osaku EF, Albert J, Costa C, et al: Effects of Neuromuscular Electrical Stimulation of the Quadriceps and Diaphragm in Critically III Patients: A Pilot Study. Crit Care Res Pract 2018; 2018:4298583

46. Silva PE, Babault N, Mazullo JB, de Oliveira TP, et al: Safety and feasibility of a neuromuscular electrical stimulation chronaxie-based protocol in critical ill patients: A prospective observational study. J Crit Care 2017; 37:141-148

47. Patsaki I, Gerovasili V, Sidiras G, Karatzanos E, et al: Effect of neuromuscular stimulation and individualized rehabilitation on muscle strength in Intensive Care Unit survivors: A randomized trial. $J$ Crit Care 2017; 40:76-82

48. Kho ME, Truong AD, Zanni JM, Ciesla ND, et al: Neuromuscular electrical stimulation in mechanically ventilated patients: a randomized, sham-controlled pilot trial with blinded outcome assessment. $J$ 
Crit Care 2015; 30(1):32-39

49. Vieira PJ, Chiappa AM, Cipriano G, Jr., Umpierre D, et al: Neuromuscular electrical stimulation improves clinical and physiological function in COPD patients. Respir Med 2014; 108(4):609-620

50. Desai SV, Law TJ, Needham DM: Long-term complications of critical care. Crit Care Med 2011; $39(2): 371-379$

51. Needham DM, Davidson J, Cohen H, Hopkins RO, et al: Improving long-term outcomes after discharge from intensive care unit: report from a stakeholders' conference. Crit Care Med 2012; 40(2):502-509

52. Yeh DD, Ortiz-Reyes LA, Quraishi SA, Chokengarmwong N, et al: Early nutritional inadequacy is associated with psoas muscle deterioration and worse clinical outcomes in critically ill surgical patients. J Crit Care 2018; 45:7-13

53. Okeke EB, Mou Z, Onyilagha N, Jia P, et al: Deficiency of Phosphatidylinositol 3-Kinase delta Signaling Leads to Diminished Numbers of Regulatory T Cells and Increased Neutrophil Activity Resulting in Mortality Due to Endotoxic Shock. J Immunol 2017; 199(3):1086-1095

54. Weijs PJ, Looijaard WG, Beishuizen A, Girbes AR, et al: Early high protein intake is associated with low mortality and energy overfeeding with high mortality in non-septic mechanically ventilated critically ill patients. Crit Care 2014; 18(6):701

55. Fremont RD, Rice TW: How soon should we start interventional feeding in the ICU? Curr Opin Gastroenterol 2014; 30(2):178-181

56. Plank LD: Protein for the critically ill patient-what and when? Eur J Clin Nutr 2013; 67(5):565-568

57. National Heart L, Blood Institute Acute Respiratory Distress Syndrome Clinical Trials N, Rice TW, Wheeler AP, et al: Initial trophic vs full enteral feeding in patients with acute lung injury: the EDEN randomized trial. JAMA 2012; 307(8):795-803 